\title{
DISCUSSION
}

\section{THE JAMES-LANGE THEORY OF THE EMOTIONS AND THE SENSATIONALISTIC ANALYSIS OF THINKING}

Professor Titchener's latest discussion of the James-Lange theory of the emotions ${ }^{1}$ seems, to the writer at least, to form an interesting parallel to some phases of the recent controversy over the analysis of thought processes. In his study of the emotions James "brought us back to the crude and raw of actual experience "; ${ }^{2}$ Titchener has given $u^{3}$ a description of the way in which an 'imaginal mind' does its thinking - an account unexcelled in clarity and vividness, which ranks with the James emotion chapters in power of stimulating the reader to careful detailed introspection. Yet James, in his emphasis on the organic factors in emotion, overlooked the elemental affective consciousness itself, and not a few psychologists to-day hold that Titchener and others, ${ }^{4}$ in emphasizing the sensational constituents of thought, leave out of account its non-sensational constituents, its 'meaning aspect' ${ }^{5}$ or 'relational elements.' ${ }^{\text {' }}$ Further, several of Titchener's arguments ${ }^{7}$ against the James-Lange theory of the emotions may be turned, almost as they stand, against the purely sensationalistic analysis of the thought processes. Such a turning of the argument against this later phase of sensationalism is the purpose of the present discussion.

On the negative side, Titchener points out (p. 48I) the inconclusiveness of the argument that because I cannot experience or imagine an emotion without organic sensations, therefore the emotion must consist in organic sensations. Similarly, of course, as Calkins ${ }^{6}$ and Angell ${ }^{5}$ have already shown, a disproof (if such be possible!)

1 Text-book of Psychology. 1910. Part II., pp. 474-484.

2 Ibid., p. 479.

3 Experimental Psychology of the Thought Processes. 1909. Cf. esp. pp. 7-22; $184-186$.

CC. esp. Colvin: A Marked Case of Mimetic Ideation. Psychologrcal BulleTIN, 7, 1910, 260-268.

${ }^{5}$ Angell: Lecture delivered at Columbia University, Feb. 3, 1911; also Psychology, Ch. X., esp. pp. 245-249 (4th edition, 1910).

- Calkins: Professor Titchener on the Thought Processes. Psychological Bulletro, 7, I9ro, 293-297; Introduction to Psychology, rgor, pp. 130 ff.; A First Book in Psychology, Ch. VIII., Appendix, Sec. VIIL., 362 ff.

7 Text-book, pp. $48 \mathrm{I}-482$. 
of the existence of 'imageless thought' carries with it no disproof of 'meaning aspects' or 'relational elements' of consciousness as nonsensational. The writer, for one, never caught an 'imageless thought' in her own mind, but seems very clearly to herself to have caught non-sensational content along with the sensational, not only in 'thinking' proper, but also in imagining and perceiving.

On the positive side, Titchener gives two main arguments against the sensationalistic theory of the emotions. In the first place, he appeals to the testimony of introspection. A group of organic sensations is and remains just a group of organic sensations. Something more must be added to such a group to make of it a true emotion, and that something more is found in the affective elements of pleasantness and unpleasantness. In the same way introspection seems to many psychologists to show that a complex of images and sensations is and remains a complex of images and sensations; that something more-call it 'relational elements,' 'meaning aspect,' or what you will-must be added before it becomes 'meaning' or 'thought.'

In the second place, Titchener says, emotion and organic sensation are not the same thing, because the two vary, to some extent at least, independently. But the same is true, by Titchener's own showing, of images and 'meaning' in our thinking. Emotion and organic sensations vary independently of each other in their intensity, their quality, and their temporal relations. ${ }^{8}$ With regard to the temporal rise and fall of meaning consciousness introspection is extremely difficult, and whether or not such meaning consciousness can be said to have an intensity is doubtful. But the consciousness of meaning certainly seems to have both clearness and quality, or kind, and to both of these attributes the variability argument may be applied. ${ }^{9}$

With regard to clearness, just as "there are a quiet joy and a boisterous joy," but "there is no evidence that the former is less intense than the latter," 8 so for one person the sensational content of the "feeling of but" may be "a flashing picture of a bald crown . . . combined with an emphatic attitude," 10 while for another it may be merely a vaguely localized fleeting kinesthetic image. That is to say, the sensational content for the first person is much clearer and more complete than for the second. Yet I think that even the sensationalists would hesitate to say that the meaning of 'but' is any less clear for the second person.

- Text-book, p. $4^{82}$.

${ }^{9}$ Calkins: Psychological Bulletin, 7, pp. 296-297.

${ }^{10}$ Trtchener : Experimental Psychology of the Thought Processes, p. 185. 
Again, to apply the independent variability argument to quality, or kind, of meaning-content and sensation-content: for Titchener 'meaning' itself is "represented by the blue-gray tip of a kind of scoop ..." ; for one of his students it is the "mental unrolling of a white scroll"; for another "a horizontal line with two short verticals. ..."11 Must we then conclude that for each of these persons the consciousness of 'meaning' is an entirely different thing? It seems hardly possible, for, as Miss Calkins has pointed out, ${ }^{12}$ they understand each other when they use the word. The logical conclusion is then, that the kind of image content is itself unimportant, so long as it 'represents' or 'carries' (I think the second of 'Titchener's terms a very exact expression of what seems to happen) the real meaning-content-in this case the relational consciousness of withinness, which is common to all these different varieties of the consciousness of 'meaning.' In other words, just as Titchener concludes that "the sensations of the organic reaction cannot be identified with the emotion, ${ }^{13}$ so the same kind of reasoning shows that the images which 'carry' the meaning-content cannot be identified with the meaning-content.

This conclusion is further corroborated by the fact that the independent variability of image-content and meaning-content holds not only for different persons, but for the same person at different times. If I may illustrate from my own case, I am, like Titchener, of a strongly imaginal 'mixed' type, with visual and kinesthetic imagery predominating. It is often, therefore, relatively easy for me to catch the sensation-image-content that 'carries' the meaningcontent. But the puzzling thing, if the sensationalists are right, is that the image-content, when caught, turns out to vary so much from time to time, even when the meaning-content is the same. Take, for example, that same case of the consciousness of 'meaning' itself. Observations carried on during only a few days gave the following list of 'carriers' of the meaning consciousness:

I. A box-image suggestive of one mentioned by Titchener, ${ }^{14}$ but more detailed, and visual as well as kinesthetic. In its most complete form a whitish box seen from above and a little to one side, with the lid half open showing a darkish interior. This visual image was sometimes relatively detailed, sometimes sketchy almost beyond recognition. Along with it there were more or less distinct kinesthetic

"Ibid., p. 19.

12 Psychological Bulletin, 7, p. 296.

${ }^{13}$ Trtchener: Texi-book, p. 483.

14 Titchener: Psychology of the Thought Processes, Appendix, p. 213, note 24. 
images, either of bending over and peering in (images located in back of neck and eyes), or of lifting up the lid (an image in hand and arm). Sometimes one kind of kinesthetic imagery was present, sometimes the other. I never detected both on the same occasion.

2. A visual image of a pair of eyes looking into mine. Color and surroundings usually indefinite, but $I$ seem to be looking into and beyond the eyes. Kinesthetic imagery or sensations such as usually accompany visual attention.

3. Visual image of word 'meaning.' Sometimes on a gauzy, half transparent background, again standing out in space, half concealing space behind. No kinesthetic imagery to be detected.

4. Visual image of eyes as in 2 , but with the eyes looking toward my right. Kinesthetic tendency to turn my own head and eyes in same direction.

5. Visual verbal image, without the transparent background, but with a kinesthetic image (head and eyes) of looking away from word toward the right. The visual image often very sketchy and fleeting.

6. Sketchy visual image of sign-post or arrow, pointing away from me and toward the left. Kinesthetic image of looking in direction indicated.

7. A tactual-motor (often also auditory) verbal image. This occurred in combination with any one of the other six images, but even this could not be detected as invariably present. It often preceded and was replaced by one of the other images. On the two or three occasions when it occurred alone it 'carried' no 'meaningcontent' at all, and I discovered that while saying the word over to myself my attention was really directed elsewhere.

Here are, then, six different sets of images as carriers of the meaning of 'meaning.' Must the meaning-content be different in all six cases? The answer of introspection is prompt and emphatic. 1,2 and 3 all carry exactly the same meaning-content-meaning is that which is within something else. The relational consciousness of 'within-ness' is somehow present in each case, as it is in the examples which Titchener gives. In 4,5 and 6 , on the other hand, the meaningcontent is somewhat different-meaning is that which is pointed at by something else. The relational part of this consciousness might perhaps be indicated by 'from $x$ to $y$,' where $x$ and $y$ are images which may themselves vary, but which always stand in the from-to relation. To these two different kinds of relational consciousness, the withinness and the from-to-ness, correspond the two slightly different sig- 
nifications which the word 'meaning' has for the observer. It will be noticed that whereas in 4,5 and 6 the kinesthetic imagery, like the meaning-content, is practically the same, in 1,2 and 3 there is no one kind of sense-content that is constant. It seems hardly possible, therefore, if this introspective record is correct, to hold that the meaning-content common to all three can be identical with any of the sensory-imaginal-content.

Examples might be multiplied. The above shows an instance in which a probably non-spatial relation or meaning is 'carried' in spatial terms. There are other cases where definitely spatial meaning-contents seem to include non-spatial relations. The verb 'to replace,' for example, means to me one of two things: it may mean to put an object back in the same place where it was; or it may mean to put an object in a place formerly occupied by another. The image-content of each of these two meanings is varied, depending largely on circumstances and especially on context. But the meaning-content is for each meaning constant. It includes, in Miss Calkins's terminology, the 'relational element' of in-ness (probably spatial), the temporal relations of now and before, and the non-spatial, non-temporal relations of same and other. In the first meaning of 'replace' it is the 'same' thing (image of whatever kind it may be) that is in the 'same' place (usually visual-kinesthetic image), but the 'in'-ness is 'other' than 'before.' For the second meaning of the word, it is an 'other' thing in the 'same' place as 'before.'

I do not wish to give the impression that all the images which carry the meaning of words and sentences are for me variable, for quite the contrary is the case. Not only have I a relatively fixed number-form, days-of-the-week form, and months-of-the-year form of which I make constant use, but the image-content of many words and phrases seems to vary from time to time only in clearness and detail, not in quality. Thus my own consciousness of 'but' is carried by a fleeting image of hand-movement closely connected with the explosive character of the tactual-motor-auditory image or sensation of the word. And my consciousness of 'essence' is carried by a visual image of a few dark layers or folds (of covering or drapery) to the right of and over (apparently partially covering) a pinkish blotch, accompanied by a distinctly unpleasant tactual-motor image which seems to be a remnant of shivering or shrinking. Whether the affective toning is due to the idea of 'bare essence,' or is a reminiscence of earlier struggles with Hegel's Logic, I do not know, At 
any rate, practically the same sensational-imaginal-content occurs whenever I think of 'essence.' But I do not believe, in spite of that fact, that my consciousness of the meaning of 'essence' is any more definite or more stable than is my consciousness of the meaning of 'replace' or of 'meaning.' Im Gegenteil! Yet the image-content of 'meaning' is variable, while the image-content of 'essence' is constant. The testimony of my own introspection, then, would be that meaning-content cannot occur alone in consciousness without any sensational or imaginal content. Yet the two are not the same thing, but the meaning-content which is 'carried by' image-content is just that relational consciousness which introspection seems to find over and above, though intimately woven in with sensations and images.

Weliesley College

Helen D. Cook

\section{A CORRECTION}

To the Editor of the Psychological Bulletin:

Will you permit me to express my regret for two misprints in my first quotation from Titchener's $A$ Text-book of Psychology on page I7 of the January number of the Bulletin. The word 'plane' is printed for 'phase,' and asterisks are omitted before 'human experience.' Through a mistake-not that of either printer or publisher - the proof never reached me and therefore was not compared with the texts of the authors whom I quoted.

Mary Whiton Calkins

Wellestey College 